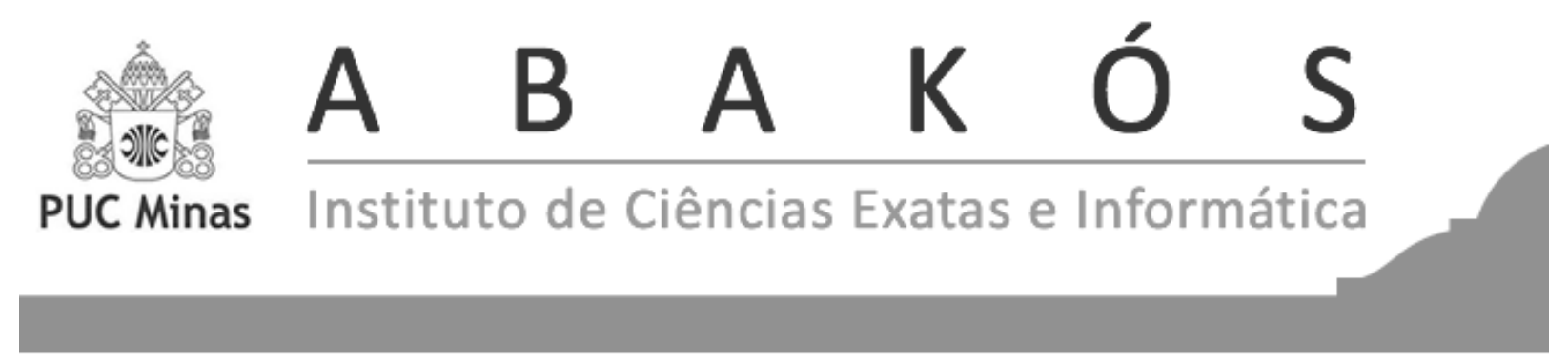

c) (i)

\title{
Simulações Envolvendo Eletroquímica: Contribuições para o Ensino Médio*
}

Simulations Involving Electrochemistry: Contributions to High School

\author{
Atenildo Gonçalves Barbosa Junior ${ }^{1}$ \\ Marcelo Machado Viana ${ }^{2}$
}

\begin{abstract}
Resumo
As simulações computacionais têm sido uma importante ferramenta de ensino frequentemente utilizada no ensino médio, contribuindo para a interatividade e inserção de tecnologias da informação e comunicação (TICs) no contexto escolar. No Ensino de Química, vários temas podem ser abordados utilizando essa tecnologia de ensino. Neste trabalho, o conteúdo eletroquímica foi escolhido por apresentar diversos exemplos tecnológicos e aplicação direta em nosso cotidiano. Inicialmente, foram realizadas uma revisão bibliográfica e uma análise das simulações deste tema disponíveis na internet, com base em critérios abordados na literatura sobre a qualidade de softwares educacionais. Alguns critérios como: facilidade de uso, recursos motivacionais, adequação dos recursos de mídia às atividades pedagógicas e conteúdos foram discutidos. Em particular, este trabalho traz uma contribuição para professores e alunos do Ensino Médio no sentido de auxiliar na escolha pela simulação a ser explorada nos processos de ensino e de aprendizagem do conteúdo eletroquímica.
\end{abstract}

Palavras-chave: Simulação computacional. Eletroquímica. Ensino médio.

* Submetido em 05/07/2020 - aceito em 16/04/2021

${ }^{1}$ Graduate in Chemistry. Universidade Federal de Minas Gerais, Av. Antônio Carlos, 6627 Pampulha, P.O. Box 1294 ZIP 31270-901, Belo Horizonte - MG, Brasil - atenildo@ hotmail.com.

${ }^{2} \mathrm{PhD}$ in Chemistry, Departamento de Química, Instituto de Ciências Exatas. Universidade Federal de Minas Gerais, Av. Antônio Carlos, 6627 Pampulha, Belo Horizonte - MG, Brasil - marcelo@gaiahresearch.com; marcelomachado@ufmg.br. 


\begin{abstract}
Computer simulations have been an important teaching tool frequently used in high school, contributing to interactivity and insertion of new information and communication technologies (ICTs) in the school context. We can approach various themes of chemistry using teaching technologies as computer simulations. We chose to work with the electrochemistry content based on its several technological examples and direct application in our daily lives. Initially, we carried out a bibliographic review about the theme, followed by an analysis of the simulations related to electrochemistry available on the internet. For this analysis, we used criteria such as ease of use, motivational resources, adequacy of media resources to pedagogical activities and contents, all addressed in the literature about the quality of educational software. In particular, this work can help teachers and students in High school choose good simulations to be explored in the teaching-learning process of electrochemistry.
\end{abstract}

Keywords: Computer simulations. Electrochemistry. High school. 


\section{INTRODUÇÃO}

A modernização tecnológica trouxe várias ferramentas para o ensino e é percebido que os alunos ingressantes estão mais conectados a essas novas tecnologias como celulares, tablets, notebooks, dentre outros meios eletrônicos. O avanço da tecnologia não ficou restrito ao ensino superior, alcançando também a Educação Básica, propiciando a utilização de aparatos tecnológicos para o ensino. Essas ferramentas são conhecidas como tecnologias de informação e comunicação (TIC). Diante da produção por parte de vários grupos de pesquisa de diversas TICs, sobretudo simulações para diferentes conteúdos, essas ferramentas podem carregar consigo algumas limitações e potencialidades que, em geral, os professores não tomam total conhecimento antes de utilizá-las em sala de aula.

O uso de simulações pode na prática não contribuir para os processos de ensino e de aprendizagem podendo gerar ou reforçar concepções alternativas ou equivocadas acerca de um conteúdo, consolidando esses saberes que os alunos constroem ao longo do período escolar e sua vivência fora do ambiente escolar que estão em desacordo com a Ciência. Na tentativa de tornar o uso de simulações mais efetivo para promover uma aprendizagem significativa (MOREIRA, 2012, p.2) é interessante que o professor tenha em mãos uma análise das limitações e potenciais contribuições que a simulação possui. Essa informação inerente à análise pode ter como referência documentos normativos como encontrados nos Conteúdos Básicos Comuns (CBC) (MINAS GERAIS, 2008) e a Base Nacional Comum Curricular (BNCC) (BRASIL, 2018).

A hipótese de alguns autores é que alguns conceitos e tópicos não são completamente entendidos devido a vários fatores que vão além da própria complexidade da disciplina. Segundo Michel et al. (2004), esses fatores envolvem a presença de concepções alternativas, o desinteresse dos estudantes, a falta de motivação, entre outros. Uma ferramenta pedagógica que poderia atenuar vários desses aspectos, que refletem em um baixo entendimento de conceitos e fenômenos químicos, é a animação de computador (simulações).

Para a compreensão do conteúdo de eletroquímica é preciso dominar os conceitos de oxidação e redução, e ter uma noção razoável sobre a representação desse fenômeno por meio da movimentação de elétrons. Ter presente o significado desses conceitos e essas representações são primordiais para o aluno transitar com eficiência entre os aspectos fenomenológicos, teóricos e representacionais no tema. Podemos perceber que muitos alunos são capazes de responder questões quantitativas e apresentam grande dificuldade de resolução de questões qualitativas (conceituais), como é relatado por Caramel e Pacca (2011). Segundo o documento emitido pela Secretaria de Educação do Estado de Minas Gerais, denominado CBC Química (MINAS GERAIS, 2008), ao envolver aspectos conceituais, as diferentes formas de abordagem possibilitam ao estudante o desenvolvimento de habilidades e atitudes de investigação e compreensão acerca dos fenômenos associados à Química. Tais aquisições baseiam-se na convivência com a linguagem simbólica/representacional dessa ciência e na apropriação de conceitos e sistemas teóricos que capacitam o aluno a dar explicações lógicas dentro desse campo de estudo e dos 
fenômenos que o cercam em sua vida em sociedade.

Em uma busca rápida na rede mundial de computadores - Internet - foi possível perceber que, para representar os fenômenos eletroquímicos, há muitas simulações disponíveis como as que foram encontradas nos sites da Iowa State University e da Mc Graw Hill. ${ }^{3}$ Para que essas simulações contribuam para o processo de ensino- aprendizagem, elas não podem apresentar erros conceituais e nem levar à formação de concepções alternativas. Por isso, a utilização de simulações em sala de aula requer uma análise crítica, para que de fato se atinja bons resultados com o seu uso.

Existem várias abordagens teóricas e concepções de ensino, que buscam entender como ocorrem os processos de ensino e de aprendizagem no ambiente escolar e que consideram características específicas do sujeito e sua relação com o ambiente onde está inserido. "Essas correntes teóricas procuram compreender o fenômeno educativo através de diferentes enfoques, muitos deles relacionados com o momento histórico de sua criação e do desenvolvimento da sociedade na qual estavam inseridas" (SANTOS, 2005, p.19).

\subsection{Abordagem da Química em sala de aula}

O currículo de Química é uma temática bastante estudada por diversos pesquisadores, grupos de pesquisa e educadores. Uma perspectiva de como ensinar ciências muito relevante e atualmente muito referenciada em artigos acadêmicos é a abordagem proposta por Alex Johnstone, intitulada "Aprendizagem multinível". Essa visão de como ensinar Química foi elaborada a partir de pesquisas teóricas, sobretudo em campo com estudantes de ensino médio e de graduação. A pesquisa foi iniciada em 1969 na Faculdade de Ciências da Universidade de Glasgow (Escócia). Johnstone destaca que a partir de 1960 ocorreu a mudança de foco e ordenação do conteúdo abordado no Ensino de Química nos currículos escolares.

A estrutura atômica e molecular e a natureza da ligação tendiam a ser mantidos até os últimos anos na escola. No entanto, agora temos uma situação em que a natureza particulada da matéria (o desenvolvimento atômico e molecular desta) e a introdução de íons e vínculos são encontradas no início da química introdutória. (JOHNSTONE, 2006, p.59).

Nessa perspectiva educacional se defende que a abordagem pode ter um aspecto totalmente macroscópico, microscópico ou representacional, bem como uma mescla entre dois ou até mesmo três aspectos.

O documento de proposta curricular para o conteúdo de Química do Ensino Médio de Minas Gerais, intitulado Conteúdo Básico Comum - CBC - (MINAS GERAIS, 2008) define os aspectos macroscópico, teórico e representacional da seguinte maneira:

$3<$ http://www.chem.iastate.edu/> e $<$ http://www.mhhe.com/> 
- $\mathrm{O}$ aspecto fenomenológico se refere aos fenômenos de interesse da Química, sejam aqueles concretos e visíveis, como a mudança de estado físico de uma substância, sejam aqueles a que temos acesso apenas indiretamente.

- O aspecto teórico relaciona-se a informações de natureza atômico-molecular, ou seja, quando se trata de propor explicações dos fenômenos, baseadas em modelos abstratos que envolvem entidades não diretamente perceptíveis ou hipotéticas, como átomos, moléculas, íons, elétrons etc.

- $\mathrm{O}$ aspecto representacional compreende informações inerentes à linguagem química, tais como as fórmulas das substâncias, equações químicas, representações dos modelos, gráficos e equações matemáticas.

O entendimento de um fenômeno físico e químico em sua totalidade é muito complexo, pois demanda a habilidade de transitar entre os três níveis conceituais de Química. Para atingir determinada competência é necessário desenvolver as habilidades embasadas nos três aspectos de abordagem gradativamente.

Uma abordagem centrada na representação significa trabalhar com equações químicas, símbolos, fórmulas e outras representações; a parte observável é pouco explorada. A abordagem submicroscópica é caracterizada pelo uso de teorias e modelos, e ainda contém o aspecto macroscópico e o representacional. O grau mais complexo de abordagem envolve os três níveis conceituais de Química: macroscópico, submicroscópico e representacional. De fato, ao transitar entre as 3 abordagens, o aluno se torna capaz de compreender a teoria e também de aprender a observar e a representar os fenômenos envolvidos na Química.

Diante da complexidade de se entender o fenômeno químico em sua totalidade, o professor precisa ponderar e trabalhar os aspectos de maneira mais clara, iniciando com a abordagem de um único aspecto partindo para uma mescla das outras abordagens.

\subsection{Habilidades cognitivas referentes ao ensino de Química}

Como o presente trabalho tem como premissa pontuar e discutir possíveis contribuições das simulações envolvendo eletroquímica, na Educação básica, é importante nos ater ao CBC - Química, documento normativo emitido pela Secretaria de Estado de Educação de Minas Gerais. O CBC estabelece quais conteúdos devem ser ministrados e quais habilidades precisam ser trabalhadas, que são apresentados no Quadro 1 para o conteúdo Eletroquímica. 
Quadro 1 - Habilidades estabelecidas pelo CBC-Química referente à Eletroquímica

\begin{tabular}{|c|c|}
\hline TÓPICOS/HABILIDADES & DESCRIÇÃO DAS HABILIDADES \\
\hline \multirow{6}{*}{$\begin{array}{c}\text { Transformações que envolvem produção de } \\
\text { energia }\end{array}$} & $\begin{array}{l}\text { Compreender o princípio básico de funcionamento } \\
\text { de uma pilha eletroquímica. }\end{array}$ \\
\hline & $\begin{array}{l}\text { Representar as transformações químicas por meio } \\
\text { de semi-reações. }\end{array}$ \\
\hline & $\begin{array}{l}\text { Consultar tabelas de potencial eletroquímico para } \\
\text { fazer previsões da ocorrência das transformações. }\end{array}$ \\
\hline & $\begin{array}{l}\text { Compreender os procedimentos utilizados para } \\
\text { efetuar cálculos de força eletromotriz de pilhas. }\end{array}$ \\
\hline & $\begin{array}{l}\text { Conhecer os constituintes e o funcionamento } \\
\text { básico das pilhas e das baterias mais comuns. }\end{array}$ \\
\hline & $\begin{array}{l}\text { Conhecer o impacto ambiental gerado pelo } \\
\text { descarte de pilhas e das baterias no ambiente. }\end{array}$ \\
\hline \multirow{3}{*}{$\begin{array}{l}\text { Transformações que envolvem consumo de } \\
\text { energia }\end{array}$} & $\begin{array}{l}\text { Compreender o princípio básico de funcionamento } \\
\text { de uma eletrólise. }\end{array}$ \\
\hline & $\begin{array}{l}\text { Exemplificar o processo de eletrólise a partir de } \\
\text { processos de obtenção de alumínio. }\end{array}$ \\
\hline & $\begin{array}{l}\text { Conhecer o impacto ambiental gerado pelo } \\
\text { processo de obtenção do alumínio. }\end{array}$ \\
\hline
\end{tabular}

Fonte: Adaptado de CBC-Química (2008).

Nesse trabalho, temos como objetivo geral fazer uma breve revisão bibliográfica acerca de trabalhos que abordam simulações envolvendo eletroquímica e selecionar algumas simulações bem como analisá-las segundo alguns critérios disponíveis na literatura. Temos como objetivos específicos analisar e discutir algumas simulações sobre eletroquímica disponíveis na internet com base nos seguintes critérios:

- Facilidade de uso: relativo à objetividade das instruções para o uso da simulação e à facilidade de percorrê-la.

- Recursos motivacionais: relativos ao interesse que o software educacional propicia e mantém no usuário.

- Adequação dos recursos de mídia às atividades pedagógicas: relativo à adequação dos recursos de hipermídia, imagem, animação, sons e efeitos sonoros às atividades pedagógicas propostas pelo software educacional.

- Conteúdos: relativo à veracidade dos conteúdos representados com a dos conteúdos presentes nas obras de referência. 


\section{REVISÃO BIBLIOGRÁFICA}

Ao pesquisar sobre tecnologia no ensino de Química, nos deparamos com uma série de artigos como: "Uso de software educacional, Objetos de Aprendizagem e Simulações no Ensino de Química" (MACHADO, 2015) e "A evolução da química computacional e sua contribuição para a educação em Química" (RAUPP et al., 2008). Constatamos que alguns deles alegam como dificuldade apresentada pelos alunos no ambiente escolar, a baixa capacidade de abstração, implicando em um baixo entendimento dos conceitos estudados. Em função dessa constatação, várias tecnomídias ${ }^{4}$ têm sido empregadas como ferramenta para auxiliar no desenvolvimento da habilidade de abstração no ensino de Química.

Machado (2015) fez uma breve revisão da literatura sobre o emprego de software educacional no Ensino de Química. Segundo ele, os autores dessas publicações estão destacando, como resultado da utilização de ferramentas tecnomidiáticas, a possibilidade de realizar uma abordagem dos conteúdos e, principalmente, um aumento da capacidade de interpretação dos fenômenos estudados na Educação Básica brasileira. Sobre isso ele afirma:

A química, entre outras ciências investigativas, também conclama para si o uso e aplicação de tecnomídias específicas para promover a efetivação da aprendizagem científica. Tais ferramentas denotam sua potencialidade, reforçando a ação docente em sala de aula de modo a favorecer colaborativa e substancialmente a aprendizagem significativa dos conteúdos escolares. (MACHADO, 2015, p.104).

O autor, por meio da revisão realizada e da análise de diversos artigos e tecnomídias, destacou aspectos positivos. Para ele, é visível a contribuição dos recursos tecnomidiáticos no desenvolvimento dos processos de ensino e de aprendizagem, que atrelados a uma abordagem adequada, agem como facilitadores na construção do conhecimento.

Como exemplo de tecnomídia, esse autor encontrou a plataforma PhET- Simulações Interativas da Universidade do Colorado Boulder que constrói simulações interativas gratuitas de Ciências e Matemática. Outras plataformas também foram encontradas e dentro das tecnomídias, nos deparamos com uma variedade de software educacional que segundo Vieira (2001 apud MICHEL et al., 2004) podem apresentar diferentes características. Paula (2015) define as simulações como programas que apresentam um grau de interatividade entre o estudante e programa, distinto das animações, predominando a representação de entidades e processos que constituem os modelos científicos.

Brasileiro e Silva (2015) defendem as simulações como uma ferramenta eficiente no sentido de proporcionar a elaboração conceitual e o desenvolvimento da capacidade de representação de fenômenos da ciência. O que confere as simulações esse potencial de contribuição

\footnotetext{
${ }^{4}$ As tecnomídias são recursos tecnológicos também designados pelo termo recursos tecnomidiáticos, uma vez que comportam aspectos de comunicação e informação atrelados às tecnologias, apresentando uma aplicação nos processos formacionais na educação contemporânea (MACHADO, 2012).
} 
para o aprendizado em sala de aula é a possibilidade de reprodução de fenômenos físicos e químicos difíceis de realizar no ambiente escolar, não obstante a capacidade de tornarem concretos os fenômenos que acontecem em escala submicroscópica.

Giordan (1999) versa que a simulação tem um papel de experimentação, onde as simulações devem possuir uma correlação entre o lúdico e o fenômeno real, com isso se torna uma ferramenta de estímulo de criação de modelos mentais pelo aluno.

Os modelos mentais servem de sistemas intermediários entre o mundo e sua representação, uma espécie de filme interno cujas cenas são formadas por imagens animadas e signos, cuja concatenação expressa o estado de coisas e dialoga com a representação que o sujeito confere à realidade (GIORDAN, 1999, p.47).

Nessa perspectiva é interessante provocar o aluno para que ele elabore seus modelos explicativos. $\mathrm{O}$ autor defende que as simulações devem fazer parte das práticas educacionais como um recurso que motiva a construção de modelos racionais.

\section{METODOLOGIA APLICADA}

Um breve olhar já nos permite identificar que há várias simulações disponíveis na rede mundial de computadores, como proposta para um ensino mais efetivo de Química no Ensino Médio. Segundo vários autores, como é caso de Michel et al. (2004), como esse tipo de software educacional possui um potencial de utilização nas escolas de Educação Básica, se torna relevante fazer uma análise dessas simulações antes de usá-las em sala de aula. Pela diversidade de simulações, escolhemos as que tratam de um conteúdo mais específico: eletroquímica.

A metodologia utilizada nesse estudo bibliográfico envolveu a seleção de artigos científicos e das simulações envolvendo o conteúdo de eletroquímica por meio de pesquisa no site Google. No caso dos artigos utilizaram-se as palavras-chave "simulação" e "eletroquímica" buscando pela temática de uso de software educacionais no Ensino de Química. As simulações estavam indicadas no sítio eletrônico do Ministério da Educação e Cultura (MEC).

Utilizamos como referencial da parte conceitual o livro Corrosão (GENTIL, 1996). Em relação à análise do ambiente e qualidade das simulações foram utilizados alguns critérios como: facilidade de uso, recursos motivacionais, adequação às atividades pedagógicas e conteúdos abordados; que são apresentados no livro Ambientes Informatizados de aprendizagem: Produção e avaliação de software educativo de Oliveira et al. (2001).

\section{RESULTADOS}

Nessa seção são apresentadas as análises de duas simulações: a de uma célula voltaica que pode apresentar diferentes eletrodos e eletrólitos e o sistema eletroquímico denominado 
Eletrólise, encontrado frequentemente nos livros didáticos do Ensino Médio.

\subsection{Célula voltaica}

A simulação de uma célula voltaica foi desenvolvida pelo grupo de pesquisa liderado por Thomas J. Greenbowe da Iowa State University e disponibilizado no site eletrônico da universidade <http://www.chem.iastate.edu/>. Todas as simulações desenvolvidas pela Iowa State University são do formato de extensão swf, e exigem que o dispositivo tenha instalados e atualizados os programas Adobe e Shockwave. É também necessário que o computador ou dispositivo utilizado para rodar as simulações esteja conectado à internet, mas é possível baixar as simulações e utilizá-las em modo off-line.

\subsubsection{Facilidade de uso}

A tela inicial da simulação é apresentada na Figura 1.

Figura 1 - Tela inicial, tutorial e opções

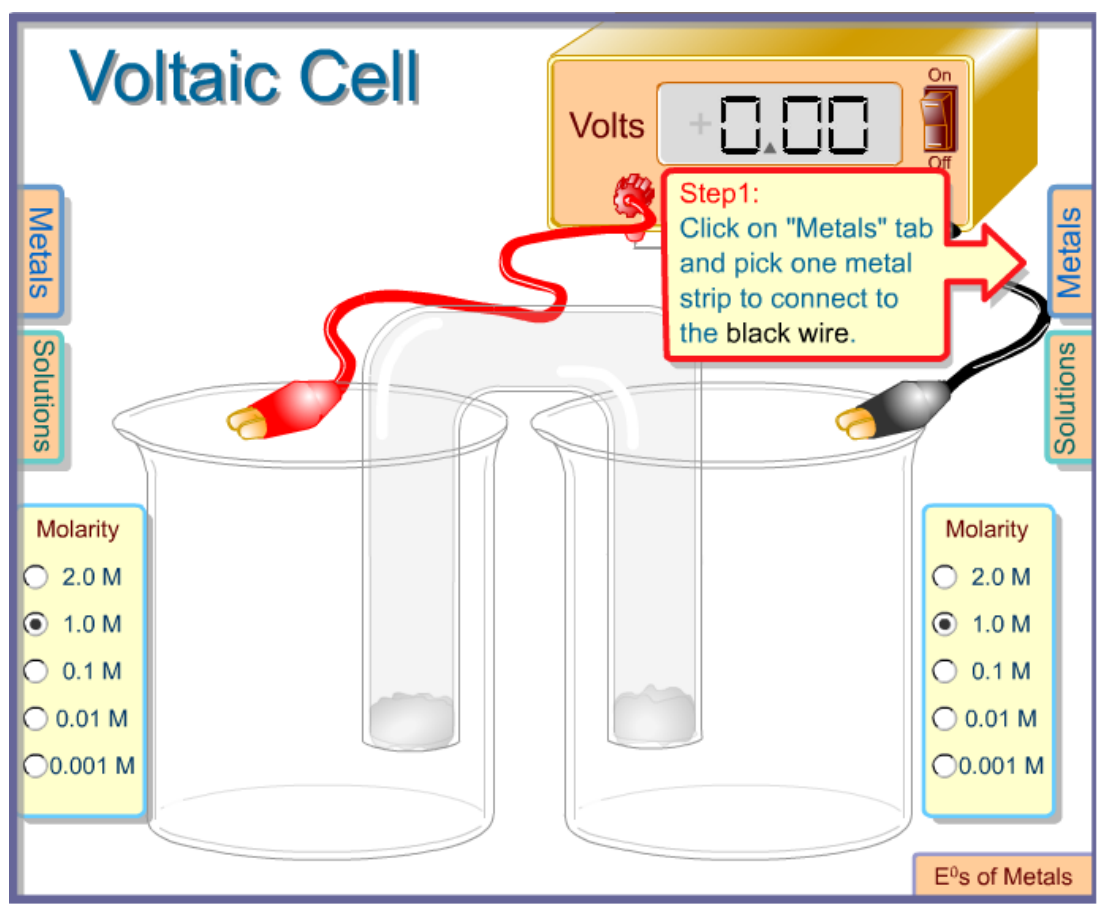

Fonte: GREENBOWE; the Chemistry Education Research

Group. VoltaicCellcomputerSimulationImage42 [digital image], 2008.

A simulação apresenta um tutorial que fornece os comandos para os alunos seguirem. Apresenta de forma acessível quatro abas localizadas nos extremos laterais, sendo duas em cada lado correspondente a metais e soluções para cada eletrodo do sistema. As abas de metais oferecem quatro opções sendo três metais (prata, cobre e zinco) e o eletrodo de hidrogênio. As abas de soluções oferecem quatro soluções: nitrato de prata, nitrato de cobre, nitrato de 
zinco e ácido clorídrico. Ainda é possível definir qual a concentração das soluções desde 0,001 molL ${ }^{-1}$ a concentração 0,1 molL $^{-1}$ variando seus valores de $10 \mathrm{molL}^{-1}$ (Figura 2). As abas e opções são de fácil marcação e objetivas, a navegabilidade é fluida de maneira que ao escolher os eletrodos e soluções basta clicar no botão para ligar a fonte, assim fechando o circuito para que a reação de redução e oxidação ocorra.

A simulação fornece a diferença de potencial da reação por meio de um voltímetro e acoplado a este dispositivo há uma lâmpada para indicar a passagem de corrente elétrica. Ao iniciar a simulação (Figura 2) clicando no botão de ligar da fonte e com os constituintes corretos, a reação de redução e oxidação começa a ocorrer.

Figura 2 - Simulação em funcionamento

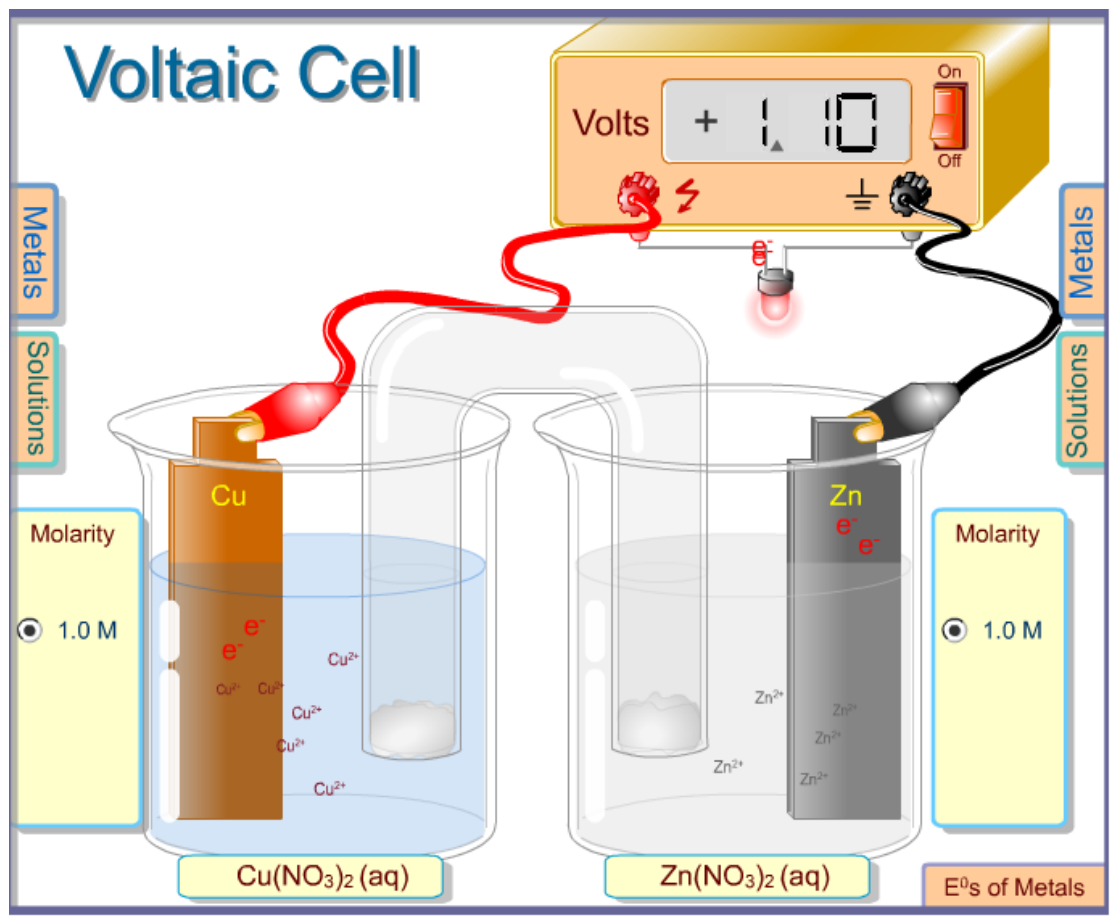

Fonte: GREENBOWE; the Chemistry Education Research

Group. VoltaicCellcomputerSimulationImage42 [digital image], 2008.

A simulação indica o fluxo de elétrons por meio da representação $\left(\mathrm{e}^{-}\right)$. Os elétrons se deslocam da placa que sofre oxidação concomitantemente com a liberação do cátion do metal para a solução. No catodo ocorre a redução da outra espécie onde os elétrons chegam até a placa por meio dos fios, passando pela fonte e acendendo a lâmpada indicando produção de energia elétrica. Os elétrons ao chegarem à placa do catodo atraem os cátions presentes em solução para a placa e ao interagirem o cátion é reduzido (desaparece).

A simulação atende bem ao primeiro critério de avaliação que é referente à facilidade de uso, pois esta apresenta instruções claras. O que pode ser um dificultador é o idioma no qual a simulação foi disponibilizada (inglês), porém a simulação apresenta botões e ícones bem indicados e organizados. Segundo Pressman (1995), o sucesso na interação do homem com a máquina por meio de uma interface computacional que leva a um processo de aprendizagem é dependente da capacidade de comunicação visual dessa interface com base no tamanho, forma, 
cor e outras características utilizadas. De forma muitas vezes subjetiva, pode-se avaliar o grau de amigabilidade entre a interface e o ser humano por meio das instruções fornecidas pelo software educativo.

A navegabilidade é um pouco debilitada, uma vez que o botão da fonte é ligado (turn on) não se pode fazer alterações no sistema, para fazer qualquer modificação é preciso reconfigurar tudo novamente. Essa limitação de navegação pode prejudicar a explicação do professor ou a visualização do aluno de uma etapa específica da simulação, a fração que se deseja observar pode ocorrer durante um período de tempo muito curto, fazendo com que o professor recorra a outro recurso para explicar a etapa de interesse. Seria interessante se houvesse a possibilidade de pausa durante toda a simulação, bem como botões de controle de velocidade (mais lento ou mais rápido) e uma linha cronológica que permitiria voltar ou avançar em qualquer instante a simulação.

\subsubsection{Recursos motivacionais}

Em relação a recursos motivacionais, o software não apresenta problematização ou desafios ao estudante, porém permite que o estudante interaja com a simulação escolhendo as soluções, placas e quando iniciar a simulação. O software apresenta um layout amigável com figuras bem definidas e organizadas, mas apresenta deficiências em pontos conceituais que serão discutidos posteriormente. A carga cognitiva presente é satisfatória, já que não é apresentada a visualização mais minuciosa em um primeiro momento; não há um exagero de informações. A simulação por si só não apresenta um desafio pedagógico, mas o professor poderia em sua prática pedagógica desenvolver um desafio e aplicá-lo em sala de aula. A utilização de simulações computacionais como atividade pedagógica deve ocorrer de forma ponderada, visto que pode gerar uma expectativa desproporcional levando a frustrações na aprendizagem (RIBEIRO; VALENTE, 2015). Nesse sentido, o acompanhamento do professor é fundamental, visto que esse poderá atuar como mediador para que não haja, por parte dos estudantes, uma superestimação do software como sendo capaz de solucionar muitos problemas de aprendizagem em eletroquímica.

\subsubsection{Adequação dos recursos de mídia às atividades pedagógicas}

Nessa simulação não se trabalha com representação de íons por meio do modelo cinético molecular, onde os íons poderiam ser tratados como espécies esféricas. A representação dos íons se dá por meio dos símbolos dos elementos e do elétron. Também é disponibilizado no canto direito inferior uma tabela de potencial de redução (Figura 3) de todas as espécies presentes no software, porém não são mostradas unidades de medida, como o volt. 
Figura 3 - Tabela de potencial de redução

\begin{tabular}{ll}
\hline $\mathrm{E}^{0} \mathrm{~s}$ of Metals & \\
$\mathrm{Mg}^{2+}(\mathrm{aq})+2 \mathrm{e}^{-}->\mathrm{Mg}(\mathrm{s})$ & -2.37 \\
$\mathrm{Zn}^{2+}(\mathrm{aq})+2 \mathrm{e}^{-}->\mathrm{Zn}(\mathrm{s})$ & -0.76 \\
$\mathrm{Fe}^{2+}(\mathrm{aq})+2 \mathrm{e}^{-}->\mathrm{Fe}(\mathrm{s})$ & -0.44 \\
$\mathrm{Ni}^{2+}(\mathrm{aq})+2 \mathrm{e}^{-}->\mathrm{Ni}(\mathrm{s})$ & -0.25 \\
$\mathrm{Sn}^{2+}(\mathrm{aq})+2 \mathrm{e}^{-}->\mathrm{Sn}(\mathrm{s})$ & -0.14 \\
$\mathrm{~Pb}^{2+}(\mathrm{aq})+2 \mathrm{e}^{-}->\mathrm{Pb}(\mathrm{s})$ & -0.13 \\
$\mathrm{Cu}^{2+}(\mathrm{aq})+2 \mathrm{e}^{-}->\mathrm{Cu}(\mathrm{s})$ & +0.34 \\
$\mathrm{Ag}^{+}(\mathrm{aq})+\mathrm{e}^{-}->\mathrm{Ag}(\mathrm{s})$ & +0.80 \\
\hline
\end{tabular}

Fonte: GREENBOWE; the Chemistry Education Research

Group. VoltaicCellcomputerSimulationImage42 [digital image], 2008.

A tabela da Figura 3 apresenta as reações somente em um sentido, com setas cheias e apenas no sentido de redução. Essa representação pode reforçar ou inserir a concepção que as reações representadas ocorrem em um único sentido. A não representação das setas duplas, equilíbrio entre os potenciais de oxidação e redução com os respectivos valores, também pode induzir à ideia de que o fenômeno não é dinâmico.

Em um segundo momento, a simulação disponibiliza duas lupas, ambas localizadas na interface das placas com as soluções. Ao clicar sobre essas lupas abre-se uma nova janela que mostra uma proposta de nível subatômico (Figura 4). Todos os constituintes da reação são representados por esferas, demonstrando a movimentação dos cátions, elétrons e o resultado das interações entre as espécies. Os átomos esféricos são representados com cores características.

A solução de cobre é representada como azul e se torna mais azul com a elevação da concentração, e é representado o descoramento da solução conforme ela sofre uma diminuição de concentração.

\section{Figura 4 - Simulação a nível atômico}

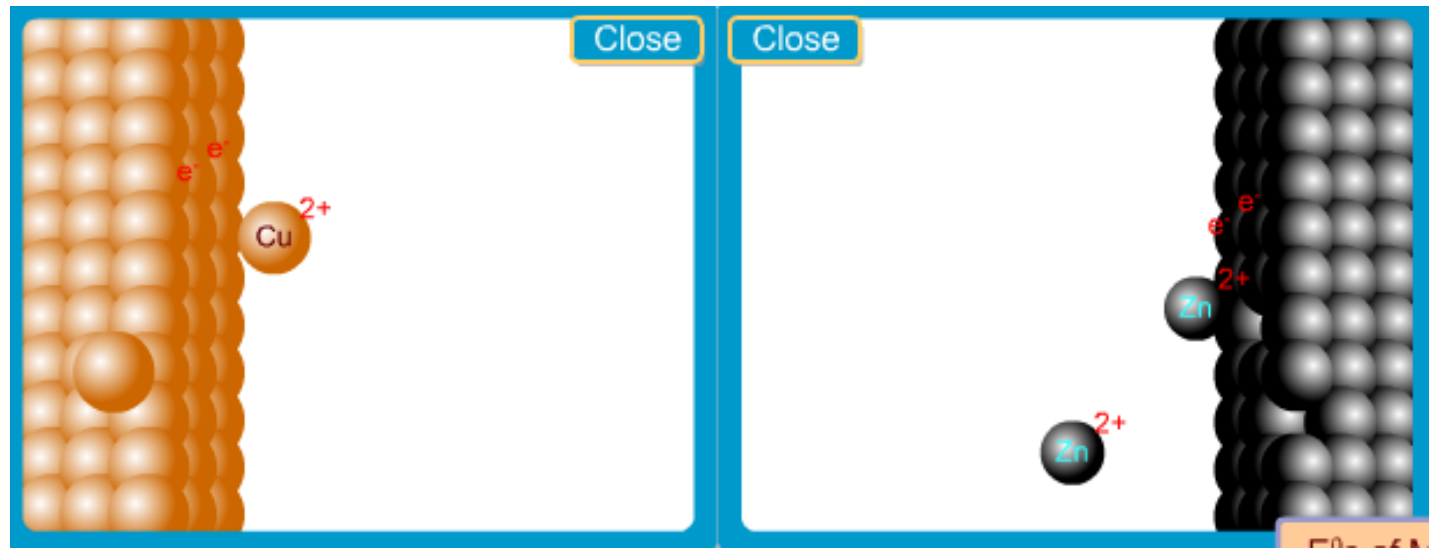

Fonte: GREENBOWE; the Chemistry Education Research

Group. VoltaicCellcomputerSimulationImage42 [digital image], 2008. 


\subsubsection{Conteúdos}

O software trabalha primeiramente com a definição de oxidação e redução como sendo um processo que envolve transferência eletrônica. Após clicar nas lupas, a reação de oxidação e redução é abordada em termos de número de oxidação (Nox). Do ponto de vista da abordagem conceitual publicada por Gentil (1996) está correto, pois a simulação utiliza as duas formas de definição de reação de oxidação e redução e não apresenta erros conceituais. Ao representar submicroscopicamente o fenômeno de oxidação e redução fica evidente a não proporcionalidade entre as espécies envolvidas que deveria ser de 1:1, pecando na premissa que as reações ocorrem em proporções definidas entre as espécies envolvidas.

A simulação apresenta características que auxiliam o professor a cumprir parte das habilidades que devem ser ensinadas ao aluno segundo o CBC-QUÍMICA (MINAS GERAIS, 2008). Podem ser contempladas as seguintes habilidades:

- Representar as transformações químicas por meio de semi-reações. A simulação por si só não contempla integralmente este tópico devido às limitações de representação das equações, mas o processo representado pela movimentação de elétrons, possibilita que o professor possa trabalhar a representação das reações químicas sem que precise utilizar a tabela de potenciais disponibilizada pela própria simulação, articulando o fenômeno com a teoria para criar e/ou explicar a representação por meio das equações químicas.

- Consultar tabelas de potencial eletroquímico para fazer previsões da ocorrência das transformações. Não seria indicado trabalhar com a tabela disponível na simulação, pois esta não indica a possibilidade de oxidação e redução de uma mesma espécie, o que poderia causar dúvidas por parte dos alunos.

- Conhecer os constituintes e o funcionamento básico das pilhas e das baterias mais comuns. Apresenta as semi-células, ponte salina, os eletrodos submergidos em solução eletrolítica conectados por meio de fio e esses ligados a um voltímetro com uma lâmpada. A representação atômica permite entender do ponto de vista conceitual este item.

A simulação não faz qualquer relação entre o fenômeno físico-químico e suas implicações ambientais, com isso o item: Conhecer o impacto ambiental gerado pelo descarte de pilhas e das baterias no ambiente; do tópico do CBC referente a transformações que envolvem produção de energia também não é contemplado pela simulação. A simulação possibilita níveis diferentes de abordagem, começando com uma representação mais simplista e partindo para uma mais complexa onde há maior detalhamento do processo estudado. Isso permite ao professor utilizá-la desde o início de sua abordagem por apresentar uma maior simplicidade e posteriormente aprofundar no conteúdo. Nesse sentido, a simulação apresenta aspectos que mesclam abordagens microscópicas e macroscópicas, em acordo com Johnstone (2006).

Seria importante que a simulação representasse a deterioração da placa oxidada e o acúmulo de massa na placa reduzida. Este aspecto não foi representado podendo levar os alunos 
a não relacionar o fenômeno de perda de massa e/ou formação de precipitado com o processo de oxidação e redução. A não representação fidedigna da realidade pode causar uma leitura deturpada do real, já que uma importante evidência da reação foi negligenciada. Nesse caso, o aluno pode ser incapaz de fazer qualquer associação entre o conteúdo estudado e a visualização na prática do fenômeno.

A solução de nitrato de cobre é apresentada com a coloração azul, e essa cor varia de acordo com a mudança da concentração da solução, seja pela escolha inicial da concentração ou pelo processo de reação, retratando o que é observado experimentalmente. Isso possibilita ao professor explorar as inferências que se pode fazer em relação há alguns aspectos visuais de um dado sistema.

É atribuído aos elétrons e íons cores. Acredita-se que para fins didáticos já que cor é uma propriedade macroscópica, seria indicado conter um aviso que as cores são somente para facilitar o entendimento visual do processo (submicroscópico) da reação de oxidação e redução. Na simulação não são trabalhadas a constituição e função da ponte salina. Seria interessante trabalhar esses aspectos, já que a ponte salina é um componente determinante para o funcionamento da pilha.

Os íons não apresentam diferença de volume entre as diferentes espécies. É de se esperar que os volumes fossem diferentes, pois são espécies distintas. Na simulação todos os átomos possuem o mesmo raio atômico, portanto o mesmo volume. O conteúdo que se trabalha em tabela periódica e periodicidade (raio atômico) não é contemplado na simulação. É fundamental que a simulação traga consigo todos os aspectos estudados que envolvam o fenômeno representado, para com isso não reforçar a Química como uma ciência sedimentada.

A simulação apresenta uma característica interessante devido a sua opção de diferentes eletrodos, soluções e concentrações. Com essa gama de variações é possível criar roteiros com diferentes objetivos como: introdução da tabela de potenciais de redução; influência da concentração sobre o potencial da reação; como ocorre a reação de oxidação e redução e como se nomeia os constituintes envolvidos nesse processo.

\subsection{Eletrólise}

A simulação de eletrólise também foi desenvolvida pelo grupo de pesquisa do professor Thomas J. Greenbowe da University State Iowa. Esse software simula um béquer ou um recipiente largo, onde é colocado dois eletrodos de metais submersos em solução de nitrato dos metais disponíveis nos eletrodos e esses, por sua vez, são conectados a uma fonte de energia com um cronômetro regressivo, um voltímetro e um amperímetro. 


\subsubsection{Facilidade de uso}

A simulação permite a alteração da corrente elétrica $(0,20 \mathrm{~V}$ a $200,00 \mathrm{~V})$, da resistência $(0,05 \Omega$ a $500,00 \Omega)$, das massas dos eletrodos $(10 \mathrm{~g}$ a $15 \mathrm{~g})$, dos metais que constituem os eletrodos: prata $(\mathrm{Ag})$, cobre $(\mathrm{Cu})$, níquel $(\mathrm{Ni})$, zinco $(\mathrm{Zn})$, e ferro $(\mathrm{Fe})$ e ainda há a possibilidade de alterar a solução aquosa presente no recipiente sendo os solutos: nitrato de prata $\mathrm{Ag}\left(\mathrm{NO}_{3}\right)_{2}$, nitrato de cobre II $\mathrm{Cu}\left(\mathrm{NO}_{3}\right)_{2}$, nitrato de níquel $\mathrm{Ni}\left(\mathrm{NO}_{3}\right)_{2}$, nitrato de zinco $\mathrm{Zn}\left(\mathrm{NO}_{3}\right)_{2}$ ou nitrato de ferro II Fe( $\left(\mathrm{NO}_{3}\right)_{2}$. Uma visão geral da simulação é mostrada na Figura 5.

\section{Figura 5 - Visão geral da simulação}

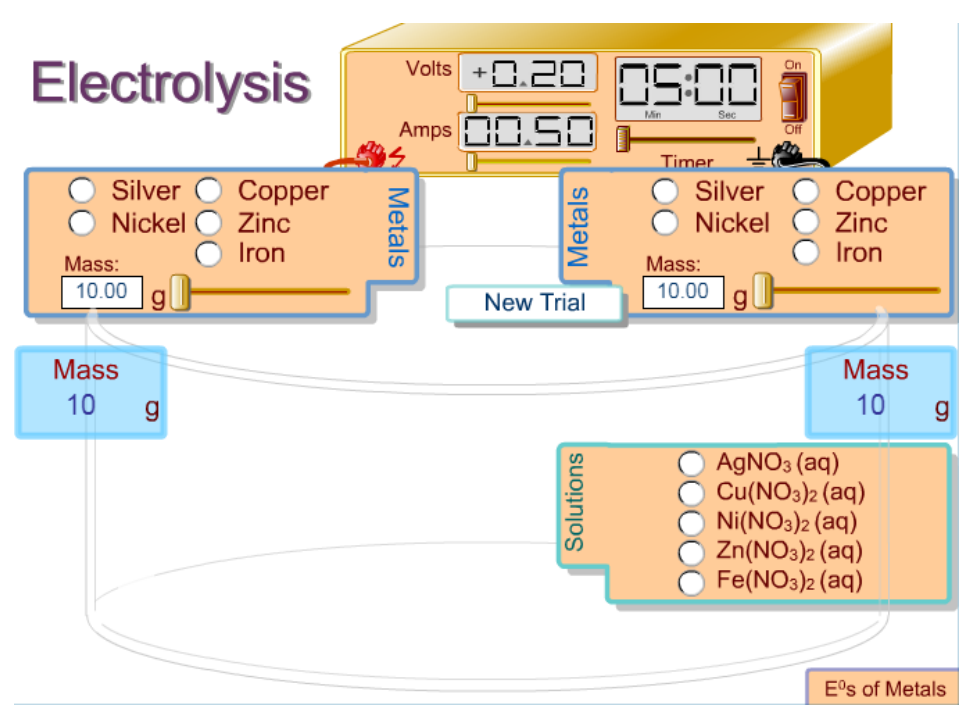

Fonte: GREENBOWE; the Chemistry Education Research Group. Electrolysis Computer Sim Image132 OLD [digital image], 2008.

Os cátions característicos da solução selecionada são orientados para o eletrodo que sofre redução (catodo) levando a um aumento da massa desse eletrodo. Em contrapartida a massa do eletrodo oxidado (anodo) é reduzida ao fornecer íons metálicos a solução e elétrons para o circuito elétrico. A Figura 6 apresenta uma imagem da simulação em funcionamento e o aviso dado em relação ao tempo. 


\section{Figura 6 - Eletrólise e aviso de tempo de reação}

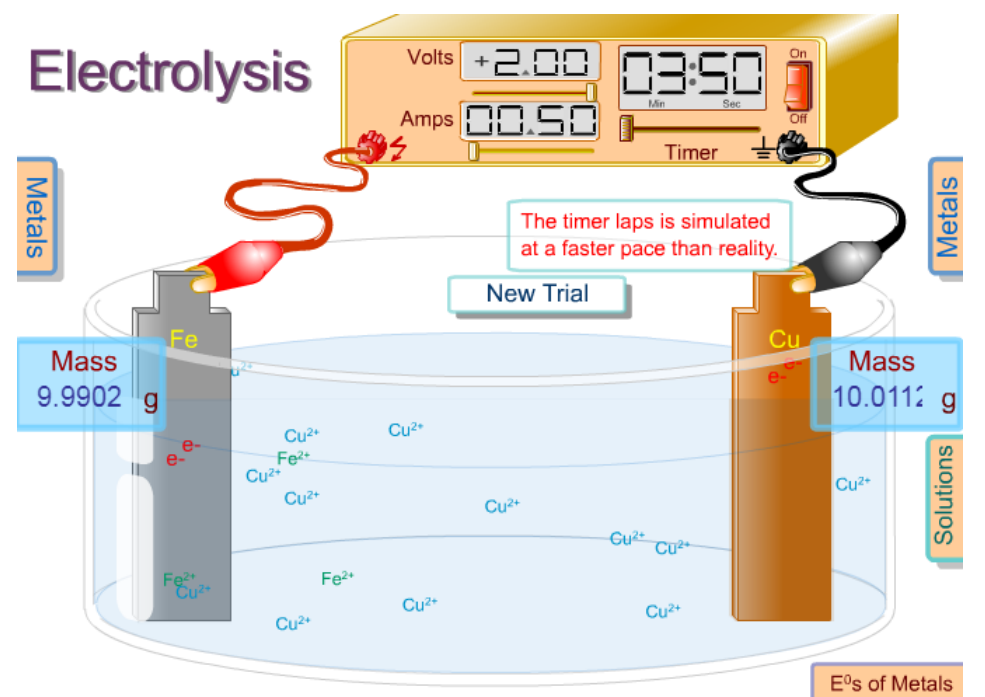

Fonte: GREENBOWE, T.J. and the Chemistry Education Research Group. Electrolysis Computer Sim Image132 OLD [digital image], 2008.

A simulação exibe os íons com a representação simbólica. Esse tipo de representação pode ser adequado já que salienta que a solução escolhida está rica no íon selecionado. Isso não exime o professor de orientar os alunos para o fato de que a representação é simplificada para fins didáticos, garantindo dessa forma a diminuição da probabilidade de a representação gerar ou reforçar concepções equivocadas dos alunos sobre as espécies envolvidas no processo de eletrólise. Caramel e Pacca (2011) relatam a importância de se desenvolver em sala de aula atividades de sondagem para identificar quais são as concepções alternativas existentes, tendo o professor um papel crucial na organização de estratégias para superação das barreiras conceituais relacionadas ao tema eletroquímica.

A simulação pode proporcionar ao aluno a realização de diferentes configurações de células eletrolíticas permitindo que esse se habitue e se familiarize com os equipamentos e reagentes envolvidos no software.

Apesar da possibilidade de escolha de cinco soluções de eletrólitos, uma sugestão seria variar os contra-íons (espécies diferentes do nitrato) como também a concentração. Caso houvesse essa opção de alteração de concentração os alunos poderiam testar, criar e confrontar hipóteses relacionadas ao rendimento da reação ou a ocorrência da reação em um determinado valor de concentração.

A exibição do valor de massa dos eletrodos in situ é um recurso muito interessante que permite ao aluno visualizar que o processo é dinâmico e que acontece em pares simultâneos; um eletrodo ganha massa enquanto o outro perde massa concomitantemente, seguindo a estequiometria da reação. Essa visão mais ampla do sistema é possível também devido à visualização da transferência eletrônica em que os elétrons são mostrados saindo do eletrodo oxidado chegando à fonte e posteriormente chegando ao eletrodo que sofre a redução, o primeiro acompanhado da liberação de íons para a solução e o segundo do deslocamento de um íon da solução para o eletrodo ao interagir com os elétrons.

A simulação não possui descrição e instruções acerca da sua utilização, mas o seu layout 
e o título utilizado são bem direcionados para o fenômeno de eletrólise. Os botões e ícones são nomeados e bem visíveis, e é apresentada uma dica referente às condições que propiciam a ocorrência da reação. A simulação é disponibilizada em inglês, mas as palavras em sua maioria são cognatas, o que pode diminuir a barreira de não domínio da língua inglesa.

\subsubsection{Recursos motivacionais}

O software permite que o aluno parta de qualquer variável do sistema, podendo alterar os eletrodos, a diferença de potencial, a massa e o tempo simulado da reação. Essa variação de sequência de procedimentos é interessante, uma vez que o aluno pode construir o sistema seguindo sua lógica, e de certa forma a não obrigatoriedade de uma sequência, pode estimular a autonomia dos alunos.

A estrutura da simulação e navegabilidade são muito dinâmicas, pois o conteúdo pode ser percorrido de maneira não linear. Não é disponibilizado um mapa indicando a sequência já realizada, o que pode gerar uma certa confusão por parte do aluno que está tendo o primeiro contato com o conteúdo. Um mapa que constasse todas as variáveis selecionadas e a ordem que foram escolhidas ajudaria na localização e na visualização de quais etapas (configurações) foram percorridas.

\subsubsection{Adequação dos recursos de mídia às atividades pedagógicas}

A simulação não apresenta desafios e nem atividades pré-estabelecidas, porém permite ao professor, de posse das variáveis disponibilizadas e de seu objetivo pedagógico, desenvolver atividades que possam favorecer o seu emprego. O layout é bem-organizado, a simulação possui uma boa resolução e é fluída, o que é um fator positivo à questão de tornar a simulação algo atrativo esteticamente. A carga cognitiva a priori parece ser adequada, embora apresente muitas informações correspondentes às soluções, eletrodos, tabela de potencial de redução, e ferramentas da fonte que estão bem distribuídas e indicadas. Vale ressaltar que determinadas simulações computacionais podem trazer concepções prévias pelo fato de utilizarem modelos simplificados, o que pode comprometer o aprendizado do estudante (NETO; BORGES, 2012; MEDEIROS; MEDEIROS, 2002). Nesse sentido, o uso de mais de uma estratégia de ensino e de aprendizagem é recomendável. Como exemplo, para o conteúdo eletroquímica, o uso de aulas experimentais ou demonstrativas associadas a criação de situações-problemas podem facilitar a aprendizagem do fenômeno físico-químico estudado.

O que poderia tornar a simulação mais interessante seria a apresentação das espécies (íons) como esferas e contemplar também o conteúdo de raio atômico estudado em tabela periódica e periodicidade. Mesmo com a elevação da carga cognitiva, a implementação dessa sugestão poderia não ser prejudicial ao entendimento do aluno, dado que esses conteúdos pos- 
sivelmente já foram trabalhados em sala de aula. A constante utilização do conteúdo estudado e a conexão com o novo conteúdo é importante para que o aluno veja que os conteúdos se relacionam, são aplicados em diferentes contextos e a sua permanente utilização torna mais natural e robusto o conhecimento construído pelo aluno.

O software não apresenta recursos de hipertextos. Seria interessante que houvesse um hipertexto introdutório ou que gerasse curiosidade no aluno referente ao processo de eletrólise, uma vez que exemplos de aplicabilidade da técnica são diversos. A imagem e animação são nítidas e são executadas de maneira fluída (sem travamentos). É oferecido auxílio quando as condições em que o sistema foi configurado não favorecem à ocorrência da eletrólise. Se a combinação de eletrodo e a escolha da solução eletrolítica não é favorável para a ocorrência da eletrólise surge um aviso na tela (Figura 7). Embora, o aviso referente à baixa voltagem seja mostrado, pode ser que o aluno ao se deparar com o referido aviso se pergunte qual a função e o porquê de ser exigida uma voltagem mínima para que determinada reação aconteça. Mesmo que tais questionamentos não aconteçam de forma natural pelos alunos é interessante que o professor os faça para provocar maior interesse e talvez motivação para exploração da simulação pelo aluno.

\section{Figura 7 - Aviso de voltagem insuficiente}

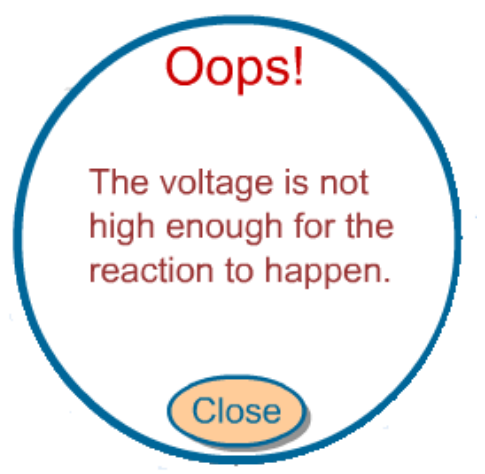

Fonte: GREENBOWE; the Chemistry Education Research Group. Electrolysis Computer Sim Image132 OLD [digital image], 2008.

O segundo aviso (Figura 8) relacionado ao tempo de reação é interessante, pois com isso os alunos podem desenvolver a ideia de que grande parte dos fenômenos químicos não ocorre instantaneamente. Nesse caso especificamente, o professor pode trabalhar perguntas voltadas para a questão econômica envolvendo o tipo e tempo de reação e quais os eletrodos mais adequados para uma determinada aplicação e ainda a questão de custo-benefício, já que o processo consome energia elétrica.

\section{Figura 8 - Aviso tempo redimensionado}

The timer laps is simulated

at a faster pace than reality.

Fonte: GREENBOWE; the Chemistry Education Research Group. Electrolysis Computer Sim Image132

OLD [digital image], 2008. 


\subsubsection{Conteúdos}

O software possui a proposta de trabalhar conceitos envolvidos na eletrólise. A partir da utilização de simulação, foi observado que de modo geral, o software cumpre bem esse quesito, a representação segue as descrições de uma célula eletrolítica presente no livro Química de Mortimer e Machado (2005).

Uma célula eletroquímica é normalmente composta por dois eletrodos, onde vão ocorrer as duas semi-reações: uma de oxidação e outra de redução. O eletrodo no qual ocorre a oxidação é chamado anodo. O eletrodo em que ocorre a redução, catodo. Além desses eletrodos, a célula é composta ainda por um eletrólito, que é o meio (geralmente uma solução) em que estão imersos os eletrodos e é responsável pela condução da corrente elétrica, na forma de íons, do anodo para o catodo. Para fechar o circuito, há ainda uma ligação entre os eletrodos, por onde os elétrons migram do anodo para o catodo. (MORTIMER; MACHADO, 2005, p.298)

A descrição acima se encaixa perfeitamente na simulação, e ainda, em termos de teoria e modelo, é demonstrada a movimentação de elétrons do anodo para o catodo e os íons em solução são depositados no catodo, mostrando o aumento de massa e quando possível, a elevação da massa é acompanhada da mudança de coloração. Seria interessante que o software disponibilizasse a representação dos contra-íons para ficar evidente que a solução presente no recipiente contém de fato o sal escolhido. Cabe ao professor comunicar aos alunos essa simplificação da simulação. Outro ponto já citado, que poderia somar à viabilidade de aplicação da simulação aqui analisada, é o dessa não trazer as representações das espécies como esferas, mas somente pelo símbolo. Apesar de a simulação não abordar alguns aspectos que seriam interessantes de serem trabalhados em termos de representação, teoria e modelos, isso não caracteriza a presença de erros conceituais e ainda pode ter o benefício da simplicidade que em um primeiro contato permitiria o entendimento mais geral do processo simulado. Vale ressaltar que segundo Johnstone (2006), o aprendizado significativo sobre um determinado conteúdo pelo aluno deve ocorrer quando este é capaz de transitar de maneira natural pelos aspectos macroscópico, submicroscópico e representacional.

O professor poderia depois ou durante o uso do software, dependendo da estratégia de ensino de sua preferência, fazer comentários e propostas de atividades que achar pertinentes para consolidar o aprendizado nesse conteúdo. Um exemplo de alternativa seria questionar os alunos a respeito da representação das espécies, a não representação dos contra-íons ou solicitar aos alunos que façam um esboço de determinada configuração da simulação utilizando a representação das espécies como esferas e atentando para a questão do raio iônico.

Um equívoco recorrente na simulação desenvolvida pelo grupo de pesquisa de J. Greenbowe envolve a tabela de potencial de redução (Figura 3) que apresenta as setas indicando apenas o sentindo de redução das espécies, e os valores do potencial que não apresentam unidade de medida. O uso da tabela pode comprometer ou retardar o entendimento do processo 
físico-químico, pois não faz qualquer menção ao comportamento dual de uma espécie relativo a ser oxidada ou reduzida. Essa omissão dos prováveis comportamentos das espécies envolvidas pode fazer com que o aluno aceite o processo, ou seja, reproduza sem entender a teoria que explica o fenômeno estudado. Seria aconselhável que o professor lançasse mão de outra tabela de potencial de oxidação e redução, mais completa, e melhor formatada.

A simulação contempla de forma segura o item: Compreender o princípio básico de funcionamento de uma eletrólise do tópico de transformações que envolvem consumo de energia emitido no Currículo Básico Comum em Química (2008), devido aos cumprimentos dos critérios analisados, sobretudo os critérios referentes à carga cognitiva e ausência de erros conceituais. Outro destaque é que a simulação possibilita várias configurações de células eletrolíticas e isso permite que o professor elabore diferentes roteiros e/ou atividades com enfoque específico relacionado à eletrólise.

\section{CONSIDERAÇÕES FINAIS}

O conteúdo eletroquímica tem sido considerado de caráter complexo por estudantes e professores do Ensino Médio. A apropriação e ressignificação dos diversos conceitos envolvendo a eletroquímica, muitas vezes depende de abstração por parte dos estudantes, o que pode levar à dificuldade de aprendizagem (RIBEIRO; VALENTE, 2015). Nesse sentido, o uso de software educativo de forma planejada, com a delimitação pretendida dos conceitos a serem desenvolvidos e por meio de modelos e linguagens representacionais adequados, tem se mostrado uma estratégia pedagógica de sucesso.

As simulações analisadas neste trabalho oferecem contribuições para o ensino e aprendizagem de eletroquímica, apesar de possuírem algumas limitações. As contribuições são variadas desde o layout ao número de variáveis e detalhes abordados. Essa ferramenta de ensino pode ser utilizada para auxiliar o aluno a transitar entre os aspectos fenomenológicos, teóricos e representacionais da Química, em acordo com Johnstone (2006). É importante destacar que nenhuma simulação promove o aprendizado significativo por si só, necessitando de outros instrumentos e um bom plano pedagógico construído pelo professor. Nesse sentido, programas de formação continuada de professores são necessários para que haja a atualização profissional para lidar com as novas demandas do ensino.

O educador, ao ler as análises feitas neste trabalho, poderá ter um aporte teórico mais detalhado para decidir qual simulação utilizar, em qual momento e/ou como utilizá-la em suas aulas. As análises feitas não têm como objetivo classificar os programas como bons ou ruins, uma vez que apesar de terem sido desenvolvidos com base em critérios descritos na literatura, há uma subjetividade inerente. Temos aqui um ferramental robusto para que o professor planeje suas aulas mais rapidamente e de forma mais criteriosa e atenta para vários pontos importantes que em um primeiro contato são difíceis de serem notados. Permite também ao professor definir qual simulação seria mais adequada para desenvolver uma determinada atividade em sala de 
aula.

As simulações permitem diferentes níveis de interação entre o aluno e o conteúdo, mas é papel do professor conduzir o tipo de abordagem a ser adotada. Por menos interativa que seja uma simulação, o professor pode explorar essa ferramenta e desenvolver atividades em grupos, promovendo discussões e debates, principalmente em nível atômico-molecular. Em eletroquímica, a mescla de simulação com experimentos ou outros recursos visuais pode promover uma abordagem multinível, considerando os três níveis de abordagem da Química, o que possivelmente conduzirá aos processos de ensino e de aprendizado mais consolidados. 


\section{REFERÊNCIAS}

BRASIL. Ministério da educação. Base Nacional Comum Curricular, Brasília, 2018.

BRASILEIRO, L. B.; SILVA, G. R. da. Interatividade na ponta do mouse: simulações e laboratórios virtuais. In: MATEUS, A. L. Ensino de Química Mediado pelas TICs. Belo Horizonte: UFMG, 2015. p. 40-42.

CARAMEL, N. J.; PACCA, J. L. Concepções alternativas em eletroquímica e circulação da corrente elétrica. Caderno Brasileiro de Ensino de Física, v. 28, n. 1, p. 7-26, 2011.

GENTIL, V. Corrosão. 3. ed. Rio de Janeiro: LTC - Livros Técnicos Científicos, 1996.

GIORDAN, M. O papel da experimentação no ensino de ciências. Revista Química Nova na Escola, n. 10, p. 43-49, 1999.

GREENBOWE, J. T; the Chemistry Education Research Group. Original publication, Iowa State University, Ames, Iowa. 2008. Acesso em abril 2021, University of Oregon, Eugene, Oregon, USA. Disponível em: <https://chemdemos.uoregon.edu/demos/ Electrochemical-Cells-Computer-Simulation-Voltaic-Cells-Zn-Cu-Ag\# $><$ https://chemdemos. uoregon.edu/demos/Electrolysis-Computer-Simulation-OLD-Flash-based-Code $>$.

JOHNSTONE, A. H. Chemical education research in glasgow in perspective. Centre for Science Education, p. 59, 2006.

MACHADO, A. L. Uso de softwares educacionais, objetos de aprendizagem e simulações no ensino de química. Química Nova na Escola, v. 38, n. 2, p. 104-111, 2015.

MEDEIROS, A.; MEDEIROS, C. F. de. Possibilidades e limitações das simulações computacionais no ensino da física. Revista Brasileira de Ensino de Física, v. 24, n. 2, p. 77-86, 2002.

MICHEL, R.; SANTOS, F. M. T. dos; GRECA, I. M. R. Uma busca na internet por ferramentas para a educação química no Ensino Médio. Química nova na escola, v. 19, 2004.

MINAS GERAIS. Secretaria de estado de educação de minas gerais. Conteúdos Básicos Comuns de Química, SEE-MG, Belo Horizonte, 2008.

MOREIRA, M. A. O que é afinal aprendizagem significativa? Revista Cultural La Laguna Espanha, p. 1-27, 2012.

MORTIMER, E. F.; MACHADO, A. H. Química. 1. ed. São Paulo: Scipione, 2005.

NETO, H. B.; BORGES, S. M. C. O papel da informática educativa no desenvolvimento do raciocínio lógico. 2012. Disponível em: <http://www.multimeios.ufc.br/arquivos/pc/pre-print/ O_papel_da_Informatica.pdf> Acesso em: 24 de Janeiro de 2021.

OLIVEIRA, C. C.; COSTA, J. W.; MOREIRA, M. Ambientes informatizados de aprendizagem: produção e avaliação de software educativo. Série Prática Pedagógica, Papirus, Campinas, 2001.

PAULA, H. F. Interatividade na ponta do mouse: as tecnologias de informação e comunicação, o ensino e a aprendizagem de ciências naturais. In: MATEUS, A.L. Ensino de Química mediado pelas TICs. Belo Horizonte: UFMG, 2015. p. 169-187. 
PRESSMAN, R. S. Engenharia de Software. São Paulo: Makron Books, 1995. (trad. 3a ed. americana).

RAUPP, D.; SERRANO, A.; MARTINS, T. L. C. A evolução da química computacional e sua contribuição para a educação química. Revista Liberato, Novo Hamburgo, v. 9, n. 2, p. 13-22, 2008 .

RIBEIRO, J. W.; VALENTE, J. A. Formação de professor: Tdic como ferramenta para promover formação a distância e integrar práticas no laboratório de experimentação científica. In: VALENTE, J. A.; ALMEIDA, M. E. B. (Orgs.). Uso do CHIC na Formação de Educadores: à guisa de apresentação dos fundamentos e das pesquisas em foco. Rio de Janeiro: Letra Capital, 2015.

SANTOS, R. V. Abordagens do processo de ensino e aprendizagem. Integração, n. 40, p. 19$31,2005$. 